\title{
Antisense Suppression of Potassium Channel Expression Demonstrates Its Role in Maturation of the Action Potential
}

\author{
Anne Vincent, Nathan J. Lautermilch, and Nicholas C. Spitzer \\ Department of Biology and Center for Molecular Genetics, University of California, San Diego, La Jolla, \\ California 92093-0357
}

\begin{abstract}
A developmental increase in delayed rectifier potassium current $\left(I_{\mathrm{Kv}}\right)$ in embryonic Xenopus spinal neurons is critical for the maturation of excitability and action potential waveform. Identifying potassium channel genes that generate $I_{\mathrm{Kv}}$ is essential to understanding the mechanisms by which they are controlled. Several $K v$ genes are upregulated during embryogenesis in parallel with increases in $I_{K v}$ and produce delayed rectifier current when heterologously expressed, indicating that they could encode channels underlying this current. We used antisense (AS) cRNA to test the contribution of $x K v 3.1$ to the maturation of $I_{\mathrm{Kv}}$, because $x K v 3.1$ AS appears to suppress specifically heterologous expression of potassium current by $x K v 3.1$ mRNA. The injection of $x K v 3.1$ AS into embryos reduces endogenous levels of $x K v 3.1 \mathrm{mRNA}$ in the developing spinal cord and reduces the amplitude and rate of activation of $I_{K v}$ in $40 \%$ of cultured neurons, similar to the percentage of neurons in which endogenous
\end{abstract}

$x K v 3.1$ transcripts are detected. The current in these mature neurons resembles that at an earlier stage of differentiation before the appearance of $x K v 3.1$ mRNA. Furthermore, AS expression increases the duration of the action potential in $40 \%$ of the neurons. No change in voltage-dependent calcium current is observed, suggesting that the decrease in $I_{\mathrm{Kv}}$ is sufficient to account for lengthening of the action potential. Computersimulated action potentials incorporating observed reductions in amplitude and rate of activation of $I_{\mathrm{KV}}$ exhibit an increase in duration similar to that observed experimentally. Thus $x K v 3.1$ contributes to the maturation of $I_{\mathrm{Kv}}$ in a substantial percentage of these developing spinal neurons.

Key words: maturation of excitability; delayed rectifier current; Kv3.1; antisense suppression; neuronal differentiation; spinal cord neurons; Xenopus embryos
Two general patterns of maturation of electrical excitability are apparent from investigation of embryonic nervous systems. In the first, long-duration principally $\mathrm{Ca}^{2+}$-dependent action potentials (APs) are converted to brief $\mathrm{Na}^{+}$-dependent impulses (Spitzer and Lamborghini, 1976; Gottmann et al., 1988) as a result of developmental increases in $I_{\mathrm{K}}$ that are delayed in relation to the initial expression of $I_{\mathrm{Ca}}$. In the second, APs are brief and $\mathrm{Na}^{+}$-dependent from the start (Bader et al., 1985) as a result of the early expression of $I_{\mathrm{K}}$. The ratio of $\mathrm{K}^{+}$to $\mathrm{Ca}^{2+}$ current at early stages of differentiation determines whether or not APs have a prominent $\mathrm{Ca}^{2+}$ dependence (Lockery and Spitzer, 1992) that can be significant in regulating aspects of neuronal differentiation ( $\mathrm{Gu}$ and Spitzer, 1995).

The requirement for transcription in the upregulation of delayed rectifier potassium current $\left(I_{\mathrm{Kv}}\right)$ that converts $\mathrm{Ca}^{2+}$ - to $\mathrm{Na}^{+}{ }_{-}$ dependent APs in Xenopus spinal neurons may include the expression of potassium channel genes, because $K v$ transcripts appear during the period of development of $I_{\mathrm{Kv}}$. In vivo, transcripts encoding $x K v 1.2$ are detected shortly after neural induction (Ribera, 1990), whereas mRNA encoding $x K v 1.1$ appears at larval stages and is localized in Rohon-Beard primary sensory neurons in the amphibian spinal cord as well as in spinal and trigeminal ganglia (Ribera and Nguyen, 1993). $x K v 2.2$ transcripts are expressed selectively in motoneurons (Burger and Ribera, 1996), and $x K v 3.1$ mRNA appears first in interneurons and subsequently in other cells throughout the spinal cord (Gurantz et al., 2000). $x K v 1.1, x K v 2.2$, and $x K v 3.1$ transcripts are upregulated in Xenopus spinal neurons

\footnotetext{
Received March 10, 2000; revised May 16, 2000; accepted May 26, 2000.

This work was supported by National Science Foundation Grant IBN-9603978 and National Institutes of Health, National Institute of Neurological Diseases and Stroke Grant NS07220. We thank the members of our laboratory for discussions; Steve Wat for technical support; I-Teh Hsieh for assistance with computer simulations; Anna Marnick for library research; and Tim Gomez, Devorah Gurantz, Paul Kingston, and Ray Smith for comments on this manuscript.

Correspondence should be addressed to Dr. Nicholas C. Spitzer, Department of Biology 0357, University of California, San Diego, 9500 Gilman Drive, La Jolla, CA 92093-0357. E-mail: nspitzer@ucsd.edu.

Copyright (C) 2000 Society for Neuroscience $0270-6474 / 00 / 206087-08 \$ 15.00 / 0$
}

in vitro during the same embryonic period (Gurantz et al., 1996, 2000). The restricted localization and sustained presence of $x K v 3.1$ mRNA in the spinal cord make it attractive for further study.

Antisense oligonucleotides have been used to suppress the appearance of delayed rectifier potassium channels in a rat pituitary cell line (Chung et al., 1995), indicating that antisense can be used to suppress the expression of voltage-gated channels as well as other components of differentiating neurons (Caceres and Kosik, 1990; Listerud et al., 1991; Wahlestedt et al., 1993; Yu et al., 1993). We used antisense (AS) cRNA to test the contribution of $x K v 3.1$ to the maturation of $I_{\mathrm{Kv}} . x K v 3.1$ AS transcripts suppress heterologous expression of potassium current in oocytes when coinjected with $x K v 3.1$ mRNA but have no effect on currents generated when coinjected with $x K v 1.1,2.1$, or 4.3 mRNA. Injection of $x K v 3.1$ AS mRNA into one cell of a two-cell stage embryo followed by in situ hybridization demonstrates that the endogenous level of $x K v 3.1$ mRNA is reduced. AS injection reduces the amplitude and the rate of activation of $I_{\mathrm{Kv}}$ in $40 \%$ of cultured neurons, similar to the percentage of neurons expressing $x K v 3.1$ transcripts (Gurantz et al., 2000). AS expression also increases the duration of the action potential in $40 \%$ of neurons. The absence of an effect on calcium current and the increase in duration of APs in computer simulations modeling the effects of $x K v 3.1$ AS on $I_{\mathrm{Kv}}$ indicate that $x K v 3.1$ contributes to the maturation of the AP in these differentiating spinal neurons.

\section{MATERIALS AND METHODS}

Oocyte injection and electrophysiological recording. Adult female Xenopus laevis were anesthetized by immersion in a $0.03 \%$ solution of benzocaine (Sigma, St. Louis, MO) for $10 \mathrm{~min}$, and ovarian lobes were removed surgically. Stage V-VI oocytes were defolliculated by gentle rocking in the presence of collagenase B $(2 \mathrm{mg} / \mathrm{ml}$; Roche Pharmaceuticals, Basel, Switzerland) in OR-2 [containing (in $\mathrm{mM}$ ) $82.5 \mathrm{NaCl}, 2 \mathrm{KCl}, 1 \mathrm{MgCl}_{2}$, and 5 HEPES, $\mathrm{pH}$ 7.5] for 60-90 min. Oocytes were stored overnight in ND-96 [containing (in mM) $96 \mathrm{NaCl}, 2 \mathrm{KCl}, 1.8 \mathrm{CaCl}_{2}, 1 \mathrm{MgCl}_{2}$, and $5 \mathrm{HEPES}$, $\mathrm{pH} 7.5$, supplemented with $550 \mathrm{mg} / 1$ sodium pyruvate, $0.5 \mathrm{~mm}$ theophylline, and $50 \mu \mathrm{g} / \mathrm{ml}$ gentamycin] and injected $18-24 \mathrm{hr}$ after defolliculation, using micropipettes (10 $\mu \mathrm{m}$ tip diameter; Sutter Instruments, Novato, CA). Capped mRNA was generated from DNA constructs using the mMessage 

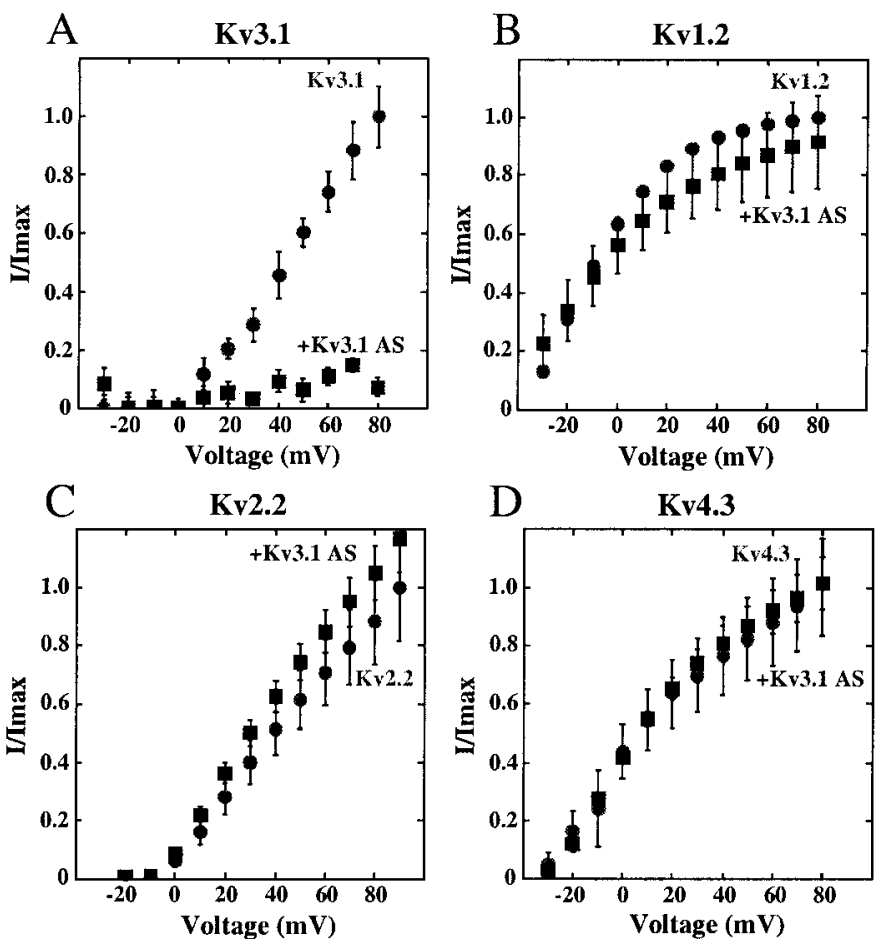

Figure 1. Antisense (AS) RNA to $x K v 3.1$ specifically inhibits the current expressed in oocytes injected with $x K v 3.1$ mRNA. Currents were recorded after injection of cRNA encoding $x K v$ genes $\pm x K v 3.1$ AS. Currents recorded in the presence of AS were normalized to those recorded from oocytes of the same clutch in the absence of AS. $A, x K v 3.1 \mathrm{AS}$ was injected at a stoichiometry of $4: 1$ with $x K v 3.1$ RNA. AS decreased the current by $86 \%$ without shifting the $I-V$ relation. $B-D, x K v 3.1$ AS had no significant effect on currents encoded by $x K v 1.1, x K v 2.1$, or $x K v 4.3$ when mRNA was injected at the same stoichiometry. Circles, $x K v$ RNA alone; squares, $x K v$ RNA plus $x K v 3.1$ AS. $n \geq 5$ for each gene.

mMachine (Ambion, Austin, TX). $x$ Kv1.1 and 2.1 cDNAs were kindly provided by Dr. A. B. Ribera (University of Colorado), and full-length cRNAs of $x K v 1.1,2.1,3.1$, and 4.3 were synthesized (Ribera and Nguyen, 1993; Burger and Ribera, 1996; Lautermilch and Spitzer, 1997; Gurantz et al., 2000). $x$ Kv3.1 AS was generated from a $3^{\prime} 1812$ bp partial clone (Gurantz et al., 2000) by in vitro transcription. mRNA $(10-50 \mathrm{ng}$ ) was injected per oocyte, and currents were recorded 2-7 d after injection using standard two-electrode voltage-clamp techniques. Data were acquired with an Axoclamp 2A amplifier and an Axolab $1100 \mathrm{~A} / \mathrm{D}$ converter (Axon Instruments, Burlingame, CA), using pClamp 5. Voltage and current electrodes were filled with $3 \mathrm{M} \mathrm{KCl}$ and had resistances of $0.5-1 \mathrm{M} \Omega$. All recordings were made at $20-22^{\circ} \mathrm{C}$, sampled at $300 \mu \mathrm{sec}$ intervals, and filtered at $1 \mathrm{kHz}$ with a Frequency Devices filter. Oocytes were perfused constantly during recordings; bath changes were achieved with $>10 \mathrm{vol}$ of new extracellular solution. The standard extracellular recording solution contained (in mM) $80 \mathrm{NaCl}, 3 \mathrm{KCl}, 5 \mathrm{MgCl}_{2}$, and 5 HEPES, pH 7.4. TTX $\left(10^{-6} \mathrm{M}\right.$; Sigma) and $10 \mathrm{~mm} \mathrm{CoCl}_{2}$ were added to block voltage-gated $\mathrm{Na}^{+}$ and $\mathrm{Ca}^{2+}$ currents, respectively. Outward potassium currents were elicited by stepping to voltages from -40 to +80 or $+90 \mathrm{mV}$ from a holding potential of $-80 \mathrm{mV}$ to activate the conductances fully (Ribera and Nguyen, 1993; Burger and Ribera, 1996; Lautermilch and Spitzer, 1997; Gurantz et al., 2000). Data were analyzed with pClamp 5; currents were normalized and plotted as mean \pm SEM. Percentage changes were calculated at each potential and averaged. Student's $t$ test was used to determine statistical significance.

Embryo injection. RNA was generated as above and injected into developing embryos at one side of the animal pole immediately after first cleavage. Five to $10 \mathrm{nl}$ of solution containing lineage tracer $(20-30 \mathrm{mg} / \mathrm{ml}$ of FITC-conjugated dextran; Molecular Probes, Eugene, OR) and the desired RNA (5-200 pg/nl) were pressure-injected (2-3 psi for 2-3 sec). Coinjected dextran was pretreated to remove RNase contamination by boiling for $10 \mathrm{~min}$ in $0.1 \%$ pyrocarbonate, followed by methanol precipitation. Injection of one cell of the two-cell stage embryo permitted onehalf of the embryo to serve as an uninjected internal control. On the basis of external morphological criteria the injected embryos underwent normal gastrulation, and survival was not impaired.

Whole-mount in situ hybridization. The nonradioactive detection method using digoxygenin-labeled probes (Harland, 1991; Ferreiro et al., 1992) was used with modifications (Burger and Ribera, 1996). $x$ Kv3.1 RNA probes were synthesized by transcription of the partial clone (Gurantz et al., 2000) in the presence of digoxygenin-labeled UTP (Roche Pharmaceuticals).
Sense and antisense probes lacked $280 \mathrm{bp}$ of the $5^{\prime}$ open reading frame (ORF) of the full-length $x K v 3.1$. Injected and control albino embryos were fixed at embryonic stages of interest in MEMPFA (3.7\% paraformaldehyde, $0.1 \mathrm{M}$ MOPS, pH 7.4, $1 \mathrm{~mm} \mathrm{MgSO}_{4}$, and $2 \mathrm{~mm}$ EGTA) at $4^{\circ} \mathrm{C}$ overnight. Hybridization was performed for $16 \mathrm{hr}$ at $60^{\circ} \mathrm{C}$. After incubation with antibody, washes were carried out over a $24 \mathrm{hr}$ period with a minimum of five changes; the final wash was carried out overnight at $4^{\circ} \mathrm{C}$. The alkaline phosphatase (AP) reaction product was developed in the presence of purple precipitating AP substrate (Roche Pharmaceuticals) for at least $12 \mathrm{hr}$. Whole-mount embryos were cleared in Murray's solution (2:1 benzyl benzoate/benzyl alcohol) and photographed with Kodak Ektachrome 160T slide film.

Culture preparation and electrophysiological recording. Embryos were produced by standard in vitro fertilization and staged according to Nieuwkoop and Faber (1967). Neural plate (stage 15) cultures were prepared (Spitzer and Lamborghini, 1976; Blair, 1983; Ribera and Spitzer, 1989) from the posterior two-thirds of the neural plate, which comprises the future spinal cord and hindbrain (Eagleson and Harris, 1990). Cells from a single embryo were plated on $35 \mathrm{~mm}$ tissue culture dishes and maintained in defined medium [containing (in $\mathrm{mm}$ ) $116 \mathrm{NaCl}, 0.67 \mathrm{KCl}, 1.31$ $\mathrm{MgSO}_{4}, 10 \mathrm{CaCl}_{2}$, and 4.6 Tris buffer, $\mathrm{pH}$ 7.8]. The cultures contained a mixed population of sensory, motor, and interneurons (Spitzer and Lamborghini, 1976; Bixby and Spitzer, 1984) as well as morphologically undifferentiated cells. Because the somitic mesoderm was not removed from the neural plate, the cultures contained myocytes as well. Whole-cell gigohm seal recording methods were used (Hamill et al., 1981). Neurons were identified on the basis of morphology, and those with short processes $(<50$ $\mu \mathrm{m}$ ) were selected (O'Dowd et al., 1988) to avoid inadequate control of the membrane voltage. An Axopatch 1-D amplifier was used in conjunction with a TL-1 data interface and pClamp 5 (Axon Instruments) for acquisition of data. Electrodes were pulled (Sutter Instruments, Novato, CA) from borosilicate glass (Drummond Scientific, Broomall, PA) and had resistances ranging between 2 and $4 \mathrm{M} \Omega$ when filled with the standard pipette solution [containing (in mM) $100 \mathrm{KCl}, 10 \mathrm{EGTA}$, and mM HEPES, $\mathrm{pH}$ 7.4]. Neurons were examined at $21^{\circ} \mathrm{C}$ using Nomarski optics at $400 \times$ magnification. Visualization of fluorescence did not interfere with cell survival or subsequent differentiation.

Whole-cell voltage-clamped potassium currents were recorded in saline consisting of (in mM) $80 \mathrm{NaCl}, 3 \mathrm{KCl}, 5 \mathrm{MgCl}_{2}, 10 \mathrm{CoCl}_{2}$, and $5 \mathrm{HEPES}$, $\mathrm{pH}$ 7.4. Sodium currents were blocked by the addition of $10^{-6} \mathrm{M}$ TTX; calcium currents were avoided by the omission of $\mathrm{CaCl}_{2}$ from the saline and the addition of $10 \mathrm{~mm} \mathrm{CoCl}$. Cells were held at $-80 \mathrm{mV}$ and stepped to potentials between -40 and $+60 \mathrm{mV}$ for $600 \mathrm{msec}$. In other experiments the calcium current was recorded in the presence of TTX and $10 \mathrm{~mm}$ $\mathrm{CaCl}_{2} ; \mathrm{MgCl}_{2}$ and $\mathrm{CoCl}_{2}$ were omitted from the bath. Pipettes were filled with (in mM) $100 \mathrm{CsCl}, 10$ tetraethylammonium-Cl (TEA), 10 EGTA, and 10 HEPES, $\mathrm{pH}$ 7.4. Membrane potential usually was held at $-80 \mathrm{mV}$ and stepped to depolarized voltages ranging between -70 and $+50 \mathrm{mV}$ in increments of $10 \mathrm{mV}$ for $50 \mathrm{msec}$. Action potentials were elicited with brief $2.5 \mathrm{msec}$ depolarizing current pulses; a steady level of current was injected to hold the resting membrane potential near $-60 \mathrm{mV}$. For these experiments the cells were bathed in a saline solution consisting of (in mM) 125 $\mathrm{NaCl}, 3 \mathrm{KCl}, 10 \mathrm{CaCl}_{2}$, and $5 \mathrm{HEPES}$, pH 7.4.

The capacitive transient was nulled electronically before establishment of the whole-cell configuration, and currents and potentials were digitized at 100 and $50 \mu \mathrm{sec}$. Cell capacitance and series resistance were determined from the capacitive current transient recorded after break in, sampled at 20 $\mu$ sec intervals. Cell capacitance was used to evaluate the membrane surface area $\left(1 \mu \mathrm{F} / \mathrm{cm}^{2}\right)$ for normalization of current amplitude to density. Leak subtraction was accomplished by using a $P /-x$ protocol, with $x=11$ hyperpolarizing subpulses (pClamp 5, Axon Instruments). Evaluation of series and input resistance and cell capacitance was aided by a program written and generously provided by Dr. Devorah Gurantz (University of California, San Diego). Measurement of times to peak or half-maximum current was accomplished with Clampfit 6 . Data are presented as mean \pm SEM. The statistical significance of differences between two groups of data was assessed using the nonparametric Mann-Whitney $U$ test, and the significance of multiple comparisons was evaluated with an ANOVA (Bonferroni's post hoc analysis); $p$ values $<0.05$ were considered statistically significant.

Population analysis. Approximately $40 \%$ of neurons express $x K v 3.1$ transcripts (Gurantz et al., 2000); thus $I_{\mathrm{Kv}}$ was not expected to be affected in all cells that are fluorescent and contain $x K v 3.1 \mathrm{AS}$. In voltage-clamp experiments the fluorescent neurons were assigned to affected $\left(\mathrm{F}_{\mathrm{as}}{ }^{*}\right)$ and unaffected categories $\left(\mathrm{F}_{\mathrm{as}}\right)$ on the basis of two criteria: a decrease in density of $I_{\mathrm{K}_{\mathrm{V}}}$ and a decrease in its activation kinetics (increase in time to halfmaximal current). When values for both at potentials of $+20,+40$, and $+60 \mathrm{mV}$ exceeded $2 \mathrm{SD}$ from mean values for nonfluorescent $(\mathrm{NF})$ control neurons recorded in the same culture dish, they were designated $\mathrm{F}_{\mathrm{As}^{*}}$; for a normal distribution only $5 \%$ of cells are expected to be in this category. The remaining neurons were designated $\mathrm{F}_{\mathrm{As}}$. The percentage of change in $I_{\mathrm{KV}}$ density and activation kinetics was calculated at each potential and averaged. For experiments in which action potentials (AP) were recorded, assignment was determined by the measurement of AP duration at $0 \mathrm{mV}$, following the same convention, and the mean percentage of change was calculated. 


\section{6 cell Neural tube Tailbud}

A

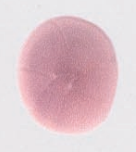

B

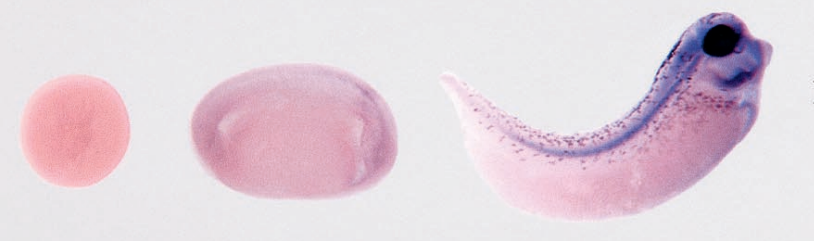

C
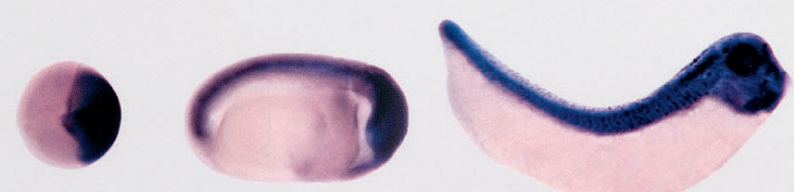

Non-injected controls, Antisense probe

Non-injected controls, Sense probe

\section{Antisense-injected,
Sense probe \\ Antisense-injected
Sense probe}
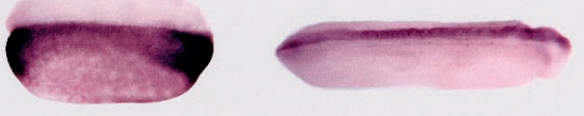

D

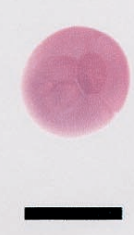

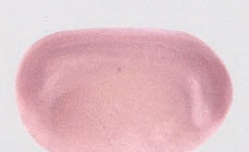

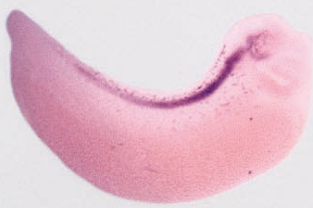

Antisense-injected, Antisense probe

\section{RESULTS}

\section{Injection of $x K v 3.1$ AS RNA specifically suppresses $x K v 3.1$ current in oocytes}

On the basis of previous work demonstrating $x K v 3.1$ transcripts in $\sim 40 \%$ of cultured neurons (Gurantz et al., 2000), we sought to identify their contribution to the maturation of $I_{\mathrm{Kv}}$ by using AS RNA. The specificity of $x$ Kv3.1 AS was examined in oocytes by coinjection of RNA encoding a member of each of the four subfamilies of voltage-activated potassium channels presently cloned from Xenopus. Currents elicited from oocytes injected with $x$ Kv3.1 mRNA were reduced by $86 \%$ when fourfold more $x K v 3.1$ AS RNA was coinjected (Fig. $1 A ; p<0.01$ ), with no apparent effect on the current-voltage relationship. In contrast, coinjection of the same stoichiometric ratio of $x K v 3.1$ AS RNA with cRNA encoding $x K v 1.1,2.2$, and 4.3 did not decrease peak current or affect their current-voltage relationships (Fig. $1 B-D$ ). These data suggest that $x K v 3.1$ AS RNA specifically reduces $x K v 3.1$ current in oocytes.

\section{$x K v 3.1$ AS reduces expression of endogenous xKv3.1 mRNA}

In vivo expression of $x K v 3.1$ was observed by whole-mount in situ hybridization with an AS probe for the first time at embryonic stage 22 in the anterior part of the spinal cord, consistent with previous observations (Gurantz et al., 2000). No reaction product was observed of embryos probed with $x K v 3.1$ sense RNA (Fig. 2A). Expression of the gene increased into the posterior spinal cord with further development and spanned its entire length by stage 30 (Fig. 2B). After injection of one cell of a two-cell stage embryo with $x K v 3.1$ AS RNA, these transcripts were visualized in the spinal cord using a sense probe (Fig. $2 C$ ). Moreover, transcripts were detected only on one side of the spinal cord, consistent with each cell of a first cleavage stage embryo, giving rise to the majority of the right or left side of the embryo (Klein, 1987). Restriction of AS to dorsal structures may be attributable to the exclusion of message from the yolk-rich gut region or to specific degradation. The detection of exogenous $x K v 3.1$ AS RNA in a stage $30(\sim 1.5 \mathrm{~d})$ embryo is concordant with the long half-life of injected RNA (6-8 hr; Harland and Misher, 1988; Kintner, 1988). AS-injected embryos hybridized with an antisense probe revealed that endogenous $x K v 3.1$ expression was reduced in one-half of the embryo, coincident with the presence of the injected AS RNA (Fig. 2D); expression was not reduced on the side derived from the uninjected blastomere. These results demonstrate (1) that injected $x K v 3.1$ AS RNA is present throughout the developmental period examined, concurrent with upregulation of $x K v 3.1$, (2) that the cRNA injection protocol delivers $x K v 3.1$ AS to the spinal cord, and (3) that the $x K v 3.1$ AS leads to a decrease in $x K v 3.1$ mRNA on the injected side of the embryo.

\section{Whole-cell recordings of $I_{\mathrm{Kv}}$ demonstrate that AS $x K v 3.1$ RNA reduces peak current and activation kinetics in a subpopulation of neurons}

$I_{\mathrm{Kv}}$ develops in cultured neurons (Barish, 1986; O'Dowd et al., 1988 ) in a manner similar to its development in vivo (Desarmenien et al., 1993). Differentiation of $I_{\mathrm{Kv}}$ requires the synthesis of new mRNA during a critical period (Ribera and Spitzer, 1989). $x$ Kv3.1 transcripts appear early during development, encode delayed rectifier potassium current, and are found in $\sim 40 \%$ of primary spinal neurons by $18-22 \mathrm{hr}$ in culture (Gurantz et al., 2000). Does expression of the $x K v 3.1$ gene play a critical role in the upregulation of $I_{\mathrm{Kv}}$ ? To address this issue, we coinjected one cell of two-cell stage embryos with $x K v 3.1$ AS RNA with a fluorescent FITC-dextran tracer and prepared cultures from neural plate stage embryos. We 


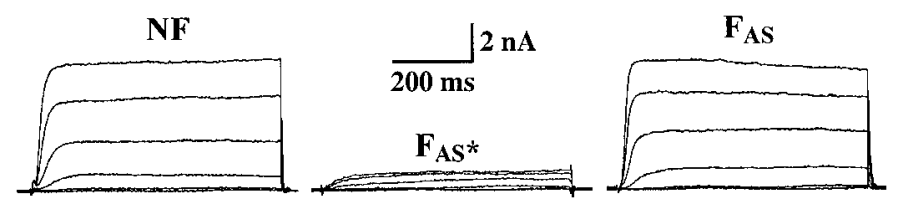

Figure 3. Inhibition of expression of $I_{\mathrm{Kv}}$ in cultured neurons after injection of $x K v 3.1$ AS RNA into a single blastomere of two-cell stage embryos. FITC-dextran was coinjected to identify neurons containing AS. Wholecell currents elicited from a holding potential of $-80 \mathrm{mV}$ and steps from -40 to $+60 \mathrm{mV}$ reveal two subpopulations of neurons. One population, $F_{A S^{*}}$ (fluorescent AS-injected, affected) neurons, has reduced $\mathrm{I}_{\mathrm{Kv}}$ amplitude and activation kinetics. The other, $F_{A S}$ (fluorescent AS-injected, unaffected) neurons, exhibits currents that are not different from those of nonfluorescent (NF) controls. The records are from three neurons at 18-22 $\mathrm{hr}$ in culture.

then examined whole-cell currents in individual neurons at $1 \mathrm{~d}$ in vitro when $I_{\mathrm{Kv}}$ normally has achieved its mature density and kinetics of activation (O'Dowd et al., 1988).

Injection of $x K v 3.1$ AS RNA reduces $I_{\mathrm{Kv}}$ in a subpopulation of neurons, consistent with the presence of AS in neurons and suppression of the levels of $x K v 3.1$ RNA (Fig. 2). The tracer is found in all cell types, including neurons, myocytes, and morphologically undifferentiated cells. Currents were elicited from neurons held at $-80 \mathrm{mV}$ and stepped to voltages from -40 to $+60 \mathrm{mV}$. Outward current was detected first at steps to $0 \mathrm{mV}$; steady-state currents were measured and plotted against command potentials. Wholecell recordings from nonfluorescent (NF) neurons confirmed previous results obtained from uninjected embryos (Gurantz et al., 2000 ), validating their use as internal controls. Recordings of $I_{\mathrm{Kv}}$ from fluorescent $(\mathrm{F})$ neurons revealed two subpopulations when compared with NF controls (Fig. 3). Preliminary analysis indicated that both the density and rate of activation of $I_{\mathrm{Kv}}$ were reduced in $40 \%$ of F cells. Accordingly, we sorted F cells into two categories: affected $\left(\mathrm{F}_{\mathrm{AS}^{*}}, 40 \%\right)$ and unaffected $\left(\mathrm{F}_{\mathrm{AS}}, 60 \%\right)$, on the basis of differences in density and time to half-maximal activation $\left(t_{1 / 2 \max }\right)$ $>2$ SD from values for NF cells recorded from the same culture dish (Fig. 4). Because neurons were analyzed in different cultures on different days, comparisons of density and $t_{1 / 2 \max }$ were made for each day to partition the neurons into $\mathrm{F}_{\mathrm{AS}}$ and $\mathrm{F}_{\mathrm{AS}}$ categories. Thus some of the data for the $\mathrm{NF}$ and $\mathrm{F}_{\mathrm{AS}^{*}}$ categories overlap in the aggregate data set illustrated in these figures. Significantly, although the amount of AS inhibition varied within the $\mathrm{F}_{\mathrm{AS}}$ * subpopulation, the percentage of cells in the affected category is similar to the percentage of neurons that have been shown to express $x K v 3.1$ transcripts (Gurantz et al., 2000). A $62 \pm 1 \%$ reduction in density of $I_{\mathrm{Kv}}$ is seen in $\mathrm{F}_{\mathrm{AS}^{*}}$ neurons (Fig. $4 A$, Table $1)$. A correlated decrease in $t_{1 / 2 \max }$ of $I_{\mathrm{Kv}}$ is observed in $\mathrm{F}_{\mathrm{AS}}$ neurons, and $t_{1 / 2 \max }$ is $166 \pm 6 \%$ of control (Fig. $4 B$, Table 1 ). In $\mathrm{F}_{\mathrm{AS}}$ neurons $I_{\mathrm{Kv}}$ density and $t_{1 / 2 \max }$ are not significantly different from that recorded from NF control neurons. These results suggest that $x K v 3.1$ normally contributes to the upregulation of $I_{\mathrm{Kv}}$ in a subpopulation of spinal neurons.

\section{Uncapped sense $x K v 3.1$ mRNA does not affect expression of $I_{\mathrm{Kv}}$}

To test further the specificity of $x K v 3.1$ AS in decreasing $I_{\mathrm{Kv}}$, we injected sense RNA with sequence complementary to that of the AS. This RNA was not capped and did not contain a translational start site, to prevent expression of exogenous $x K v 3.1$. Injection of one cell of a two-cell stage embryo with $x K v 3.1$ sense RNA and a fluorescent tracer allowed visualization of cells that received the sense transcripts. The density of $I_{\mathrm{Kv}}$ in $\mathrm{F}_{\mathrm{S}}$ cells is not different from that in NF controls (Fig. $5 A ; p>0.7$, NS). Additionally, measurements of activation kinetics of $I_{\mathrm{Kv}}$ demonstrate that $\mathrm{F}_{\mathrm{S}}$ and NF control cells are not different (Fig. $5 B ; p>0.5$, NS). These data indicate that $x K v 3.1$ sense RNA has no effect on $I_{\mathrm{Kv}}$ density and activation kinetics and argue that the effects of $x K v 3.1$ AS are not attributable to spurious toxicity from RNA injection.

\section{AS suppression of $x K v 3.1$ RNA results in longer action potentials}

Because the injection of $x K v 3.1$ AS RNA demonstrates that $x K v 3.1$ transcripts contribute significantly to $I_{\mathrm{Kv}}$ in a subset of neurons, we determined whether its effect extended to the action potential (AP) as well. We predicted that the AP would increase in duration (Lockery and Spitzer, 1992) in the same percentage of neurons that undergo a decrease in $I_{\mathrm{Kv}}$ after injection of $x K v 3.1$ AS RNA. Using current-clamp recording, we depolarized neurons to elicit APs (Fig. 6). Analysis of $\mathrm{F}$ neurons revealed that $40 \%$ had an AP duration $>2$ SD longer than that of NF controls (Fig. 7), equal to the percentage of neurons that exhibited a decrease in amplitude and increase in $t_{1 / 2 \max }$ of $I_{\mathrm{Kv}}$ as a result of injection of $x K v 3.1 \mathrm{AS}$ RNA and similar to the percentage of neurons normally expressing
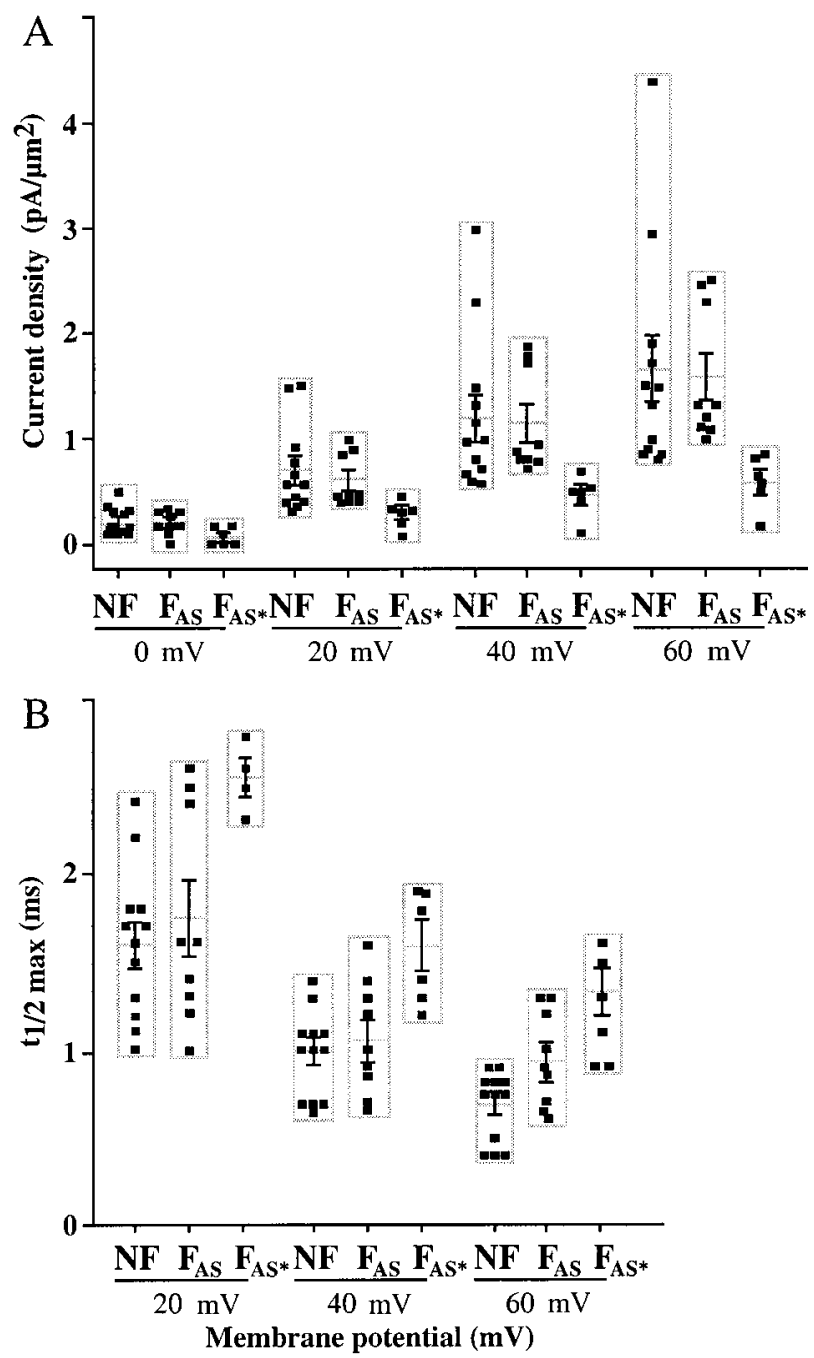

Figure 4. Properties of $I_{\mathrm{Kv}}$ in $\mathrm{F}_{\mathrm{AS}}$ neurons. Currents were recorded at $18-22 \mathrm{hr}$ in culture. $A$, Current densities of $\mathrm{F}_{\mathrm{AS}^{*}}$ neurons are reduced relative to those of $\mathrm{NF}$ and $\mathrm{F}_{\mathrm{AS}}$ neurons. $\mathrm{F}_{\mathrm{AS}}$ cells show a mean $62 \pm 1 \%$ decrease in current density at 0 to $+60 \mathrm{mV}(p<0.01)$, whereas $\mathrm{F}_{\mathrm{AS}}$ cells have currents that are not different from NF controls. The boxes include all measurements from cells at a particular voltage. Horizontal bars indicate the means for these measurements, and vertical bars indicate SEMs. NF, Nonfluorescent; $F_{A S}$, fluorescent, but unaffected by AS; $\mathrm{F}_{A S^{*}}$, fluorescent, affected by AS. Values were designated $\mathrm{F}_{\mathrm{AS}^{*}}$ when they exceeded $2 \mathrm{SD}$ from the mean values for NF neurons in the same culture dish and thus in some cases overlap the values for NF neurons recorded in other cultures; $n=27$. $B$, Times to half-activation $\left(t_{1 / 2 \max }\right)$ of $\mathrm{F}_{\mathrm{AS}}$ neurons are increased relative to those of $\mathrm{NF}$ and $\mathrm{F}_{\mathrm{AS}}$ neurons. $\mathrm{F}_{\mathrm{AS}^{*}}$ cells show a $66 \pm 6 \%$ increase in $t_{1 / 2 \max }$ at +20 to $+60 \mathrm{mV}(p<0.01)$, whereas $\mathrm{F}_{\mathrm{AS}}$ cells have currents that are not different from NF controls. Values at $0 \mathrm{mV}$ are not shown because $I_{\mathrm{Kv}}$ is small and slowly activating at this potential in $\mathrm{F}_{\mathrm{AS}^{*}}$ neurons, and discrimination from noise is ambiguous; $n=27$. Noise precluded measurement from two cells at $+20 \mathrm{mV}$. 
Table 1. Properties of control and antisense-treated neurons

\begin{tabular}{|c|c|c|c|c|}
\hline \multirow[b]{2}{*}{$\underline{\text { Parameters }}$} & \multirow{2}{*}{$\begin{array}{l}\text { Controls } \\
\mathrm{NF}\end{array}$} & \multicolumn{2}{|l|}{ AS to $\mathrm{xKv} 3.1$} & \multirow[b]{2}{*}{ Significance of comparison } \\
\hline & & $\mathrm{F}_{\mathrm{AS}}$ & $\mathrm{F}_{\mathrm{AS}^{*}}$ & \\
\hline Membrane potential (mV) & $-45.3 \pm 0.6(12)$ & $-44.4 \pm 1.0(9)$ & $-45.4 \pm 0.6(6)$ & NS \\
\hline Capacitance $\left(\mathrm{pF} / \mu \mathrm{m}^{2}\right)$ & $22.9 \pm 1.2(12)$ & $22.5 \pm 1.7(9)$ & $21.4 \pm 2.0(6)$ & NS \\
\hline Input resistance $(G \Omega)$ & $1.2 \pm 0.1(12)$ & $1.4 \pm 0.2(9)$ & $1.1 \pm 0.1(6)$ & NS \\
\hline$I_{\mathrm{Kv}}$ density $\left(\mathrm{pA} / \mu \mathrm{m}^{2},+40 \mathrm{mV}\right)$ & $1.2 \pm 0.2(12)$ & $1.1 \pm 0.2(9)$ & $0.5 \pm 0.1(6)$ & $\begin{array}{l}\mathrm{F}_{\mathrm{AS}^{*}} \text { vs } \mathrm{F}_{\mathrm{AS}} p<0.05 \\
\mathrm{~F}_{\mathrm{AS}^{*}} \text { vs control } p<0.01\end{array}$ \\
\hline$I_{\mathrm{Kv}} t_{1 / 2 \max }(\mathrm{msec},+40 \mathrm{mV})$ & $1.0 \pm 0.1(12)$ & $1.0 \pm 0.1(9)$ & $1.6 \pm 0.1(6)$ & $\begin{array}{l}\mathrm{F}_{\mathrm{AS}^{*}} \mathrm{vS}_{\mathrm{AS}} p<0.05 \\
\mathrm{~F}_{\mathrm{AS}^{*}} \text { vs control } p<0.01\end{array}$ \\
\hline$I_{\mathrm{Ca}}($ peak $)\left(\mathrm{pA} / \mu \mathrm{m}^{2}\right)$ & $0.3 \pm 0.1(6)$ & & (7) & NS \\
\hline AP duration (at $0 \mathrm{mV})(\mathrm{msec})$ & $1.9 \pm 0.1(9)$ & $1.9 \pm 0.2(9)$ & $3.5 \pm 0.6(6)$ & $\begin{array}{l}\mathrm{F}_{\mathrm{AS}^{*}} \text { vs } \mathrm{F}_{\mathrm{AS}} p<0.01 \\
\mathrm{~F}_{\mathrm{AS}^{*}} \text { vs control } p<0.01\end{array}$ \\
\hline
\end{tabular}

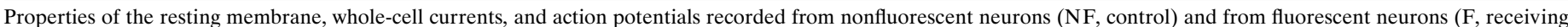

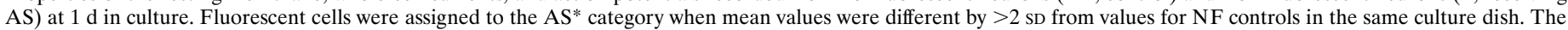
rest were placed in the AS category. Values are mean \pm SEM for $(n)$ neurons from $\geq 3$ experiments. NS, Not significantly different.
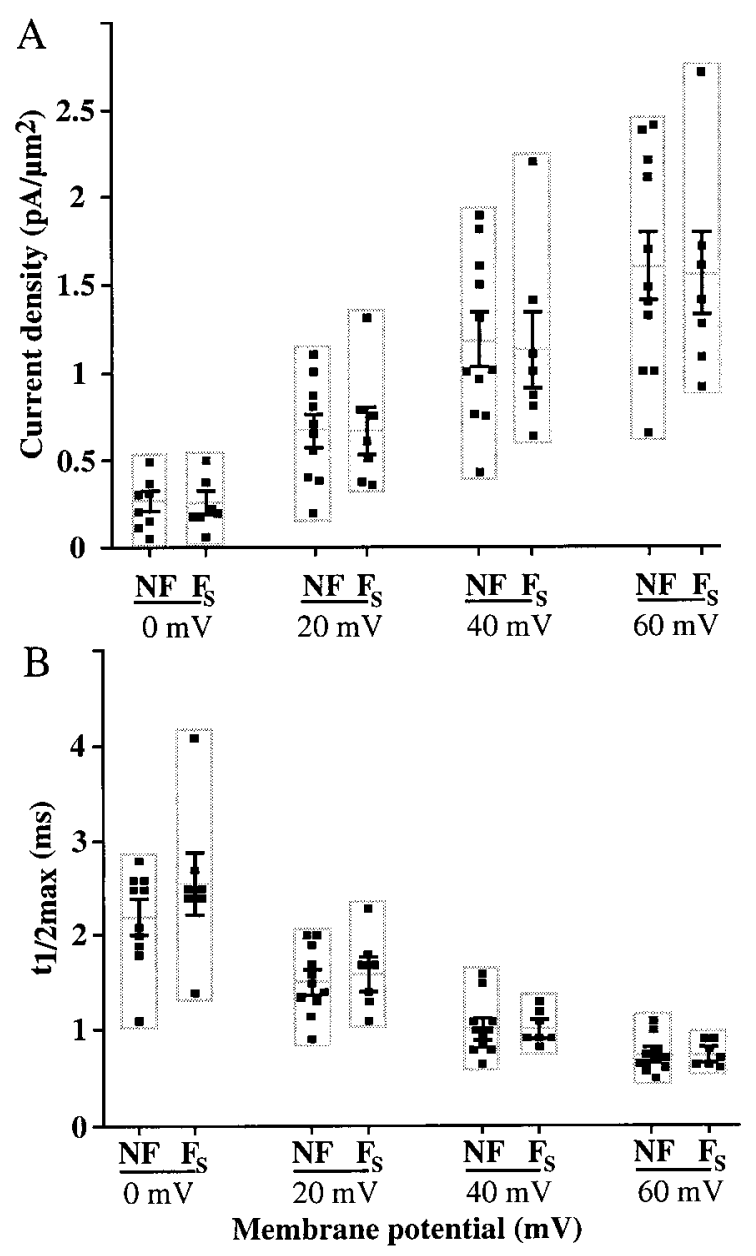

Figure 5. Injection of $x K v 3.1$ sense RNA into a single blastomere of two-cell stage embryos has no effect on the expression of $I_{\mathrm{Kv}}$ in cultured neurons. $A$, Current densities of $\mathrm{F}_{\mathrm{S}}$ and NF neurons are not different. $B$, Times to half-activation of $\mathrm{F}_{\mathrm{S}}$ and $\mathrm{NF}$ neurons are not different. Conventions are as in Figure $4 ; n=18$.

$x K v 3.1$ transcripts (Gurantz et al., 2000). The average duration of APs in NF neurons was $1.9 \pm 0.2 \mathrm{msec}$, whereas that in $\mathrm{F}_{\mathrm{AS}}$ neurons was $3.5 \pm 0.6 \mathrm{msec}$ (Table 1), resulting in a mean increase of $184 \%$ and demonstrating a substantial contribution of $x K v 3.1$ to neuronal repolarization during an AP in these cells. In contrast, the duration of APs in $\mathrm{F}_{\mathrm{AS}}$ neurons was $1.9 \pm 0.2 \mathrm{msec}$, not significantly different from that of NF controls $(p>0.05)$.

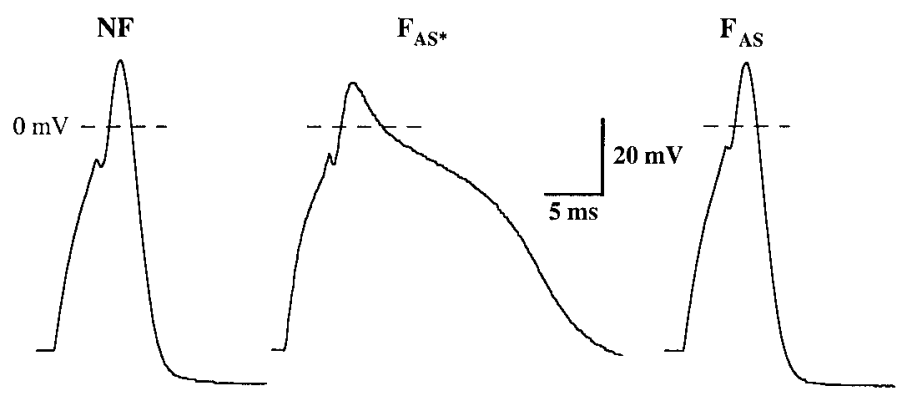

Figure 6. $x K v 3.1 \mathrm{AS}$ increases action potential duration. The AP of $\mathrm{F}_{\mathrm{AS}^{*}}$ neurons is longer in duration than that of NF and $\mathrm{F}_{\mathrm{AS}}$ neurons $(p<0.01)$, consistent with reduction of the amplitude of $I_{\mathrm{Kv}}$. The records are from three neurons at $1 \mathrm{~d}$ in culture; $n=24$.

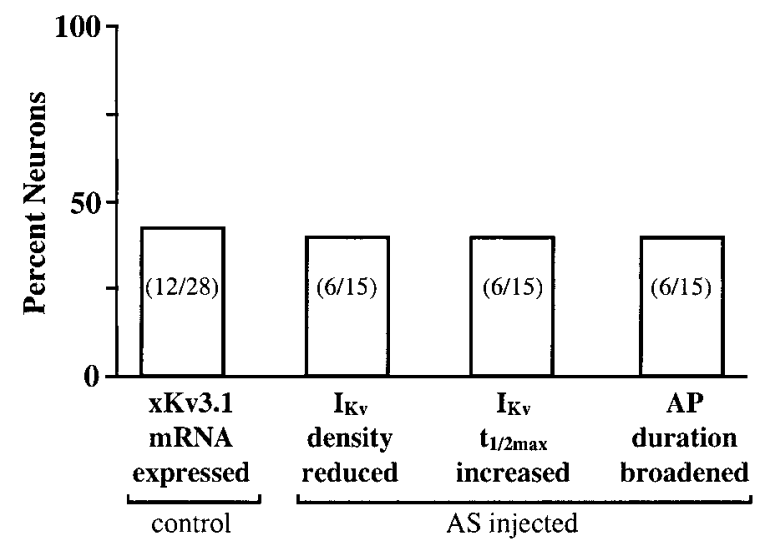

Figure 7. The percentage of neurons in which $I_{\mathrm{Kv}}$ and APs are affected by $x K v 3.1$ AS is similar to the percentage of neurons previously shown to express $x K v 3.1$ transcripts (Gurantz et al., 2000). Numbers in parentheses indicate the number of neurons affected/tested for each condition.

\section{$x K v 3.1$ AS RNA does not reduce $I_{\mathrm{Ca}}$}

The increase in AP duration after injection of $x K v 3.1$ AS RNA could result from either a decrease in outward current or an increase in sustained inward current. Accordingly, we examined calcium current $\left(I_{\mathrm{Ca}}\right)$ in $\mathrm{F}$ and NF neurons at $1 \mathrm{~d}$ in culture. Both low voltage- and high voltage-activated $I_{\mathrm{Ca}}$ were elicited by depolarization to potentials from -70 to $+50 \mathrm{mV}$ from a holding potential of $-100 \mathrm{mV}$ (Fig. 8A) (Gu and Spitzer, 1993). Comparison of currents in $\mathrm{F}$ and $\mathrm{NF}$ neurons reveals that $I_{\mathrm{Ca}}$ is not changed because of the presence of $x K v 3.1$ AS RNA (Fig. 8B), suggesting that the increased duration of the AP is attributable to 
A
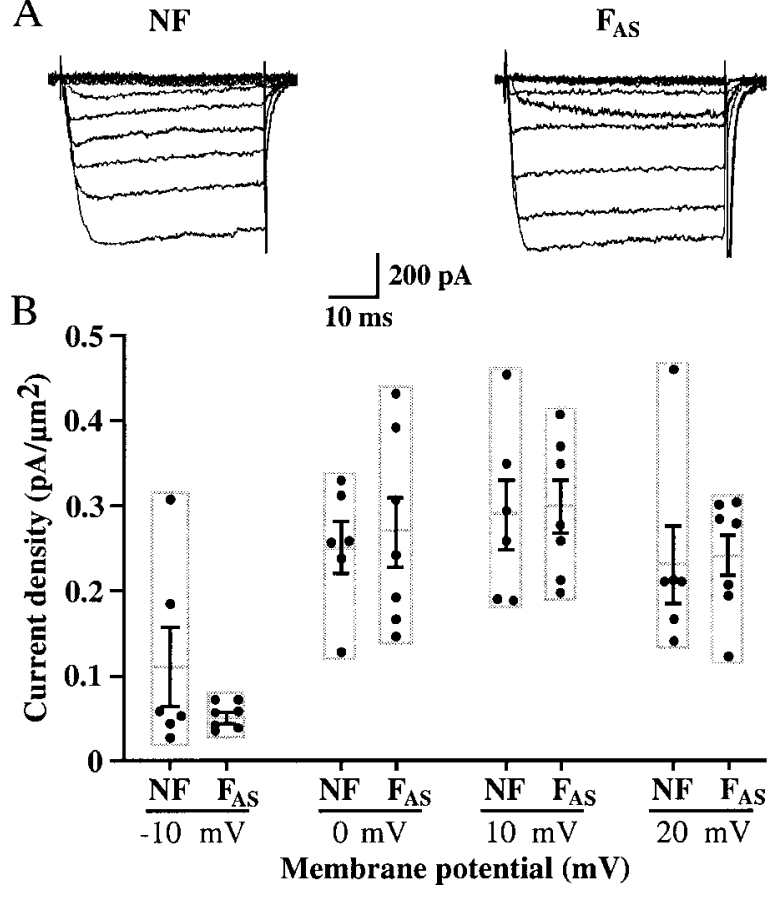

Figure 8. $I_{\mathrm{Ca}}$ is not affected by the expression of $x K v 3.1$ AS. $A$, Whole-cell voltage-clamp records of low voltage-activated and high voltage-activated calcium currents; potassium and sodium currents were suppressed pharmacologically. The records are from two neurons at $1 \mathrm{~d}$ in culture. Cells were held at $-80 \mathrm{mV}$ and stepped to potentials from -50 to $+20 \mathrm{mV}$. B. Current densities for $\mathrm{NF}$ and $\mathrm{F}_{\mathrm{AS}}$ neurons. The records are from six and seven neurons at $1 \mathrm{~d}$ in culture. Conventions are as in Figure 4. Mean $I_{\mathrm{Ca}}$ is not significantly different for these two populations. The apparent reduction in the density of calcium current at $-10 \mathrm{mV}$ likely reflects outliers in the NF population.

the effect on the expression of $x K v 3.1$ alone (Table 1). Furthermore, these data reinforce the conclusion that the $x K v 3.1$ gene product contributes significantly to the AP as well as to $I_{\mathrm{Kv}}$.

\section{Action potentials simulated with reduced $I_{\mathrm{Kv}}$ are similar to those recorded in the presence of $x K v 3.1$ AS RNA}

Specific suppression of the amplitude and $t_{1 / 2 \max }$ activation of $I_{\mathrm{Kv}}$ in a subset of neurons by $x K v 3.1$ AS RNA is accompanied by an increase in the duration of the AP. To determine whether the reduction in $I_{\mathrm{Kv}}$ is sufficient to account for the increase in impulse duration, we performed computer simulations of the AP, using a program previously developed to examine the contribution of different currents to the generation of the AP (Lockery and Spitzer, 1992; Gu and Spitzer, 1993). Simulations of voltage-clamped $I_{\mathrm{Kv}}$ and $I_{\mathrm{Ca}}$ mimic recorded currents (Fig. 9A,B). Simulation of the AP in control neurons, using values for voltage-clamped currents recorded at $1 \mathrm{~d}$ in culture, yields an impulse with a duration of 2.0 msec at $0 \mathrm{mV}$, consistent with previous modeling results (Fig. 9C) (Lockery and Spitzer, 1992). When the amplitude of $I_{\mathrm{Kv}}$ is reduced by $62 \%$ and the time to half-maximal is increased consistent with experimental recordings, the duration of the AP is $3.5 \mathrm{msec}$ (Fig. $9 C ; 175 \%$ increase). Thus the extent of suppression of $I_{\mathrm{Kv}}$ with $x K v 3.1$ AS RNA is appropriate to account for the increase in AP duration recorded experimentally.

\section{DISCUSSION}

\section{Specificity of AS suppression of $x K v 3.1$}

Contribution of a channel gene to current expression requires that synthesis of transcripts precedes appearance of the current (Ribera, 1990; Ribera and Nguyen, 1993; Burger and Ribera, 1996; Gurantz et al., 1996; Baranauskas et al., 1999) and that suppression of the current occurs when transcripts are removed or functional channels are eliminated specifically (Ribera, 1996). Previous work

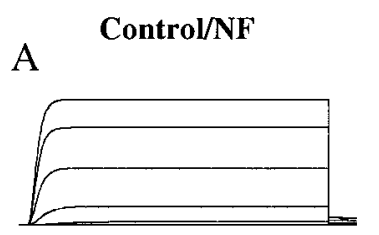

Experimental/ $\mathrm{F}_{\mathrm{AS}} *$

B
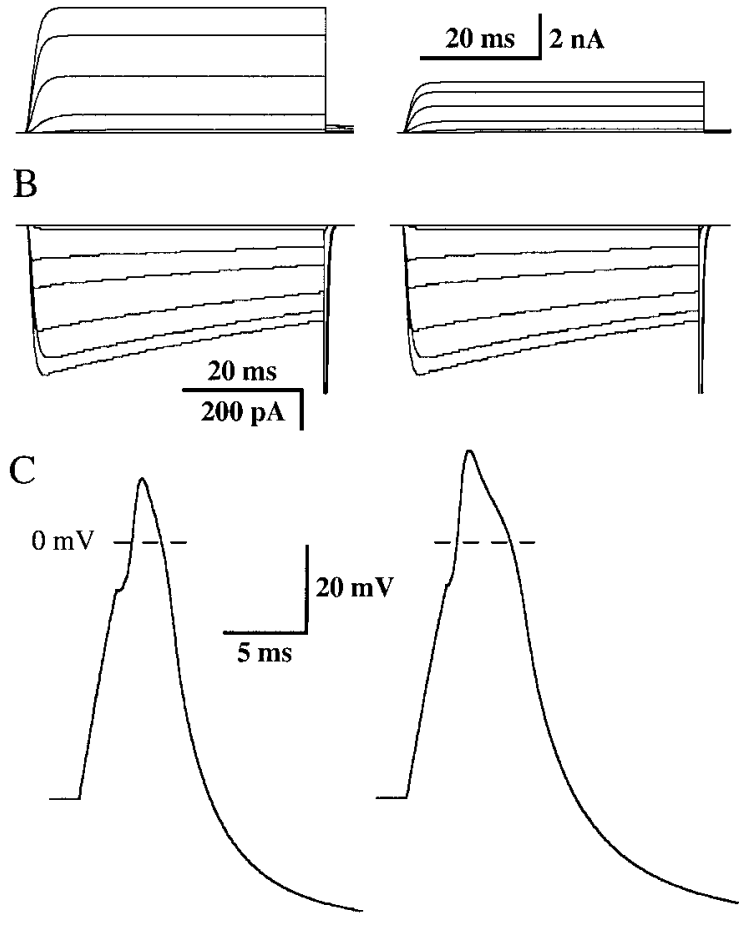

Figure 9. Computer-simulated action potentials in which $I_{\mathrm{Kv}}$ is reduced by the amounts observed experimentally are longer in duration, consistent with the increase in experimentally recorded AP duration after the suppression of $I_{\mathrm{Kv}}$ with $x K v 3.1 \mathrm{AS}$. $A$, Computer simulations of $I_{\mathrm{Kv}}$ in control and experimental conditions $\left(100 \% I_{\mathrm{Kv}}\right.$, and with reduction in density and increase in time to half-maximal activation values derived from AS experiments). $B$, Simulations of $I_{\mathrm{Ca}}$ in control and experimental conditions; the jagged nature of the traces is attributable to the plotting regime, which increases the distance between points when the rate of change of the current is small. $C$, Simulations of APs in control and experimental conditions. Modeling was performed by using a previously developed program (Lockery and Spitzer; 1992; Gu and Spitzer, 1993). Mimicking experimental recording conditions, the holding potential was set at $-60 \mathrm{mV}$, and brief $2.5 \mathrm{msec}$ depolarizing current pulses were used to elicit APs arising after the termination of the stimulus.

showed that $x K v 3.1 \mathrm{mRNA}$ is present during the period in which $I_{\mathrm{Kv}}$ matures (Gurantz et al., 2000). Here we show that expression of $x K v 3.1$ AS RNA suppresses $I_{\mathrm{Kv}}$, and conclude that transcription of the $x K v 3.1$ potassium channel gene contributes to the maturation of $I_{\mathrm{Kv}}$ in a subset of embryonic spinal neurons. This conclusion relies on the specificity of $x K v 3.1$ AS for $x K v 3.1$ mRNA, which is supported by three lines of evidence. First, $x K v 3.1$ AS suppresses current encoded by $x K v 3.1$ transcripts expressed in oocytes and has no effect on currents expressed by members of three other $K v$ subfamilies. Second, $x K v 3.1$ AS both reduces $I_{\mathrm{Kv}}$ and increases AP duration in the same percentage of neurons in which endogenous $x K v 3.1$ transcripts are expressed, making it unlikely that other genes of the $K v 3$ subfamily are affected. Third, uncapped $x K v 3.1$ sense RNA has no effect on the expression of $I_{\mathrm{Kv}}$. In situ hybridization of cultured neurons or staining with antibodies could provide structural corroboration of the functional result of the application of AS. This demonstration of the role of a specific member of the Kv3 subfamily in the maturation of $I_{\mathrm{Kv}}$ in $40 \%$ of Xenopus spinal neurons is complementary to the demonstration of the role of $K v 1$ subfamily members, using a dominant-negative strategy (Ribera, 1996).

\section{Contribution of potassium channel genes in mature nervous systems}

Functional properties of specific endogenously expressed potassium channels were identified first in a clonal rat pituitary cell line using AS oligonucleotides (Chung et al., 1995). Subsequently, the 
role of specific delayed and inward rectifier potassium channel genes in cardiac muscle was defined by suppression of activity of specific genes with AS (Feng et al., 1997; Nakamura et al., 1998; Bou-Abboud and Nerbonne, 1999; Wang et al., 1999). Suppression of A-type potassium current with AS has been reported to suppress LTP without affecting rat spatial maze learning or memory (Meiri et al., 1998). The function of $K v$ and G-protein-gated Kir genes in neuronal spike waveform, excitability, synaptic transmission, and nociception in postnatal mice has been determined by the deletion of these genes (Signorini et al., 1997; Clark and Tempel, 1998; Giese et al., 1998; Smart et al., 1998; Z hou et al., 1998, 1999). Here we demonstrate the role of transcripts of the $x K v 3.1$ gene encoding potassium channels in the embryonic development of excitability by suppression of their activity with AS. The Kv3.1 gene also is expressed in developing inferior colliculus, auditory rhombencephalon, and cerebellum (Liu and Kaczmarek, 1998; Hendriks et al., 1999; Shibata et al., 1999) and seems likely to regulate excitability in these systems as well. Because spinal neurons exhibit spontaneous calcium transients that depend on transiently expressed calcium-dependent action potentials ( $\mathrm{Ca}^{2+}$ spikes; Gu et al., 1994), the suppression of $K v 3.1$ and $I_{\mathrm{Kv}}$ could extend the developmental period during which these transients are expressed and thereby affect neuronal differentiation (Gu and Spitzer, 1995).

\section{Heterogeneity of potassium channel gene expression}

Heterogeneity of potassium channel gene expression in Xenopus spinal neurons is suggested by examination of transcripts and by the results of eliminating their contribution to $I_{\mathrm{Kv}}$. In situ hybridization and single-cell RT-PCR demonstrate that different $K v$ genes are expressed in subsets of neurons (Ribera and Nguyen, 1993; Burger and Ribera, 1996; Gurantz et al., 1996, 2000). Using a dominantnegative construct to suppress the activity of the $x K v 1$ subfamily (Ribera, 1996), the current was reduced to varying degrees in $60 \%$ of neurons expressing the construct, implying coexpression of $K v$ genes of other subfamilies. In addition, $20 \%$ of neurons expressing the construct had no detectable $I_{\mathrm{Kv}}$, consistent with expression of the $x K v 1$ subfamily alone in these neurons. These conclusions are supported by the finding that channel subunits of one subfamily do not coassemble with those from other subfamilies (Covarrubias et al., 1991; Xu et al., 1995) (however, see Shahidullah et al., 1995; Chen et al., 1996; Kerschensteiner and Stocker, 1999). Using antisense to suppress the activity of $x K v 3.1$, we show that $I_{\mathrm{Kv}}$ is reduced to $38 \%$ of its amplitude in $40 \%$ of neurons, consistent with the expression of transcripts encoded by this gene (Gurantz et al., 2000) and suggesting that the antisense is both specific and suppresses the contributions from all $x K v 3.1$ transcripts. On the other hand, no neurons that were assayed completely lacked $I_{\mathrm{Kv}}$. These observations raise the question of the difference in functional roles of these multiple potassium channels, which generate similar currents in heterologous systems. Future studies will examine differences in modulation and localization of these otherwise apparently redundantly expressed channels.

\section{REFERENCES}

Bader CR, Bertrand D, Dupin E (1985) Voltage-dependent potassium currents in developing neurones from quail mesencephalic neural crest. J Physiol (Lond) 366:129-151.

Baranauskas G, Tkatch T, Surmeier DJ (1999) Delayed rectifier currents in rat globus pallidus neurons are attributable to $K v 2.1$ and $K v 3.1 / 3.2 \mathrm{~K}^{+}$ channels. J Neurosci 19:6394-6404.

Barish ME (1986) Differentiation of voltage-gated potassium current and modulation of excitability in cultured amphibian spinal neurones. J Physiol (Lond) 375:229-250.

Bixby JL, Spitzer NC (1984) Early differentiation of vertebrate spinal neurons in the absence of voltage-dependent $\mathrm{Ca}^{2+}$ and $\mathrm{Na}^{+}$influx. Dev Biol 106:89-96.

Blair LAC (1983) The timing of protein synthesis required for the development of the sodium action potential in embryonic spinal neurons. J Neurosci 3:1430-1436.

Bou-Abboud E, Nerbonne JM (1999) Molecular correlates of the calciumindependent, depolarization-activated $\mathrm{K}^{+}$currents in rat atrial myocytes. J Physiol (Lond) 517:407-420.

Burger C, Ribera AB (1996) Xenopus spinal neurons express Kv2 potas- sium channel transcripts during embryonic development. J Neurosci 16:1412-1421.

Caceres A, Kosik KS (1990) Inhibition of neurite polarity by tau antisense oligonucleotides in primary cerebellar neurons. Nature 343:461-463.

Chen ML, Hoshi T, Wu CF (1996) Heteromultimeric interactions among $\mathrm{K}^{+}$channel subunits from Shaker and eag families in Xenopus oocytes. Neuron 17:535-542.

Chung S, Saal DB, Kaczmarek LK (1995) Elimination of potassium channel expression by antisense oligonucleotides in a pituitary cell line. Proc Natl Acad Sci USA 92:5955-5959.

Clark JD, Tempel BL (1998) Hyperalgesia in mice lacking the Kv1.1 potassium channel gene. Neurosci Lett 251:121-124.

Covarrubias M, Wei AA, Salkoff L (1991) Shaker, Shal, Shab, and Shaw express independent $\mathrm{K}^{+}$current systems. Neuron 7:763-773.

Desarmenien MG, Clendening B, Spitzer NC (1993) In vivo development of voltage-dependent ionic currents in embryonic Xenopus spinal neurons. J Neurosci 13:2575-2581.

Eagleson GW, Harris WA (1990) Mapping of the presumptive brain regions in the neural plate of Xenopus laevis. J Neurobiol 21:427-440.

Feng J, Wible B, Li GR, Wang Z, Nattel S (1997) Antisense oligodeoxynucleotides directed against Kv1.5 mRNA specifically inhibit ultrarapid delayed rectifier $\mathrm{K}^{+}$current in cultured adult human atrial myocytes. Circ Res 80:572-579.

Ferreiro B, Skoglund P, Bailey A, Dorski R, Harris WA (1992) XASH1, a Xenopus homologue of Achaete-scute: a proneural gene in anterior regions of the vertebrate central nervous system. Mech Dev 40:25-36.

Giese KP, Storm JF, Reuter D, Fedorov NB, Shao LR, Leicher T, Pongs O, Silva AJ (1998) Reduced $\mathrm{K}^{+}$channel inactivation, spike broadening, and after-hyperpolarization in $K v \beta 1.1$-deficient mice with impaired learning. Learn Mem 5:257-273.

Gottmann K, Dietzel ID, Lux HD, Huck S, Rohrer H (1988) Development of inward currents in chick sensory and autonomic neuronal precursor cells in culture. J Neurosci 8:3722-3732.

Gu X, Spitzer NC (1993) Low-threshold $\mathrm{Ca}^{2+}$ current and its role in spontaneous elevations of intracellular $\mathrm{Ca}^{2+}$ in developing Xenopus neurons. J Neurosci 13:4936-4948.

Gu X, Spitzer NC (1995) Distinct aspects of neuronal differentiation encoded by frequency of spontaneous $\mathrm{Ca}^{2+}$ transients. Nature 375:784-787.

Gu X, Olson EC, Spitzer NC (1994) Spontaneous neuronal calcium spikes and waves during early differentiation. J Neurosci 14:6325-6335.

Gurantz D, Ribera AB, Spitzer NC (1996) Temporal regulation of Shakerand Shab-like potassium channel gene expression in single embryonic spinal neurons during $\mathrm{K}^{+}$current development. J Neurosci 16:3287-3295.

Gurantz D, Lautermilch NJ, Watt SD, Spitzer NC (2000) Sustained upregulation in embryonic spinal neurons of a Kv3.1 potassium channel gene encoding a delayed rectifier current. J Neurobiol 42:347-356.

Hamill OP, Marty A, Neher E, Sakmann B, Sigworth FJ (1981) Improved patch-clamp techniques for high-resolution current recording from cells and cell-free membrane patches. Pflügers Arch 391:85-100.

Harland R (1991) In situ hybridization: an improved whole-mount method for Xenopus embryos. In: Methods in cell biology, Vol 36, Xenopus laevis (Kay B, Peng B, eds), pp 685-695. San Diego: Academic.

Harland R, Misher L (1988) Stability of RNA in developing Xenopus embryos and identification of a destabilizing sequence in TFIIIA messenger RNA. Development 102:837-852.

Hendriks R, Morest DK, Kaczmarek LK (1999) Shaw-like potassium currents in the auditory rhombencephalon throughout embryogenesis. J Neurosci Res 58:791-804.

Kerschensteiner D, Stocker M (1999) Heteromeric assembly of Kv2.1 with $K v 9.3$ : effect on the state dependence of inactivation. Biophys J $77: 248-257$

Kintner C (1988) Effects of altered expression of the neural cell adhesion molecule, N-CAM, on early neural development in Xenopus embryos. Neuron 1:545-555.

Klein SJ (1987) The first cleavage furrow demarcates the dorsal-ventral axis in Xenopus embryos. Dev Biol 120:299-304.

Lautermilch NJ, Spitzer NC (1997) The Kv4.3 Shal gene is developmentally upregulated in Xenopus embryos and encodes a potassium current modulated by arachidonic acid. Soc Neurosci Abstr 23:1738.

Listerud M, Brussaard AB, Devay P, Colman DR, Role LW (1991) Functional contribution of neuronal AChR subunits revealed by antisense oligonucleotides. Science 254:1518-1521.

Liu SQ, Kaczmarek LK (1998) Depolarization selectively increases the expression of the Kv3.1 potassium channel in developing inferior colliculus neurons. J Neurosci 18:8758-8769.

Lockery SR, Spitzer NC (1992) Reconstruction of action potential development from whole-cell currents of differentiating spinal neurons. J Neurosci 12:2268-2287.

Meiri N, Sun MK, Segal Z, Alkon DL (1998) Memory and long-term potentiation (LTP) dissociated: normal spatial memory despite CA1 LTP elimination with Kv1.4 antisense. Proc Natl Acad Sci USA 95:15037-15042.

Nakamura TY, Artman M, Rudy B, Coetzee WA (1998) Inhibition of rat ventricular IK1 with antisense oligonucleotides targeted to Kir2.1 mRNA. Am J Physiol 274:H892-H900.

Nieuwkoop PD, Faber J (1967) Normal table of Xenopus laevis (Daudin): 
a systematical and chronological survey of the development from the fertilized egg till the end of metamorphosis, 2nd Ed. Amsterdam: North-Holland.

O'Dowd DK, Ribera AB, Spitzer NC (1988) Development of voltagedependent calcium, sodium, and potassium currents in Xenopus spinal neurons. J Neurosci 8:792-805.

Ribera AB (1990) A potassium channel gene is expressed at neural induction. Neuron 5:691-701.

Ribera AB (1996) Homogeneous development of electrical excitability via heterogeneous ion channel expression. J Neurosci 16:1123-1130.

Ribera AB, Nguyen DA (1993) Primary sensory neurons express a Shakerlike potassium channel gene. J Neurosci 13:4988-4996.

Ribera AB, Spitzer NC (1989) A critical period of transcription required for differentiation of the action potential of spinal neurons. Neuron 2:1055-1062.

Shahidullah M, Hoshi N, Yokoyama S, Higashida H (1995) Microheterogeneity in heteromultimeric assemblies formed by Shaker (Kv1) and Shaw (Kv3) subfamilies of voltage-gated $\mathrm{K}^{+}$channels. Proc R Soc Lond [Biol] 261:309-317.

Shibata R, Wakazono Y, Nakahira K, Trimmer JS, Ikenaka K (1999) Expression of $K v 3.1$ and $K v 4.2$ genes in developing cerebellar granule cells. Dev Neurosci 21:87-93.

Signorini S, Liao YJ, Duncan SA, Jan LY, Stoffel M (1997) Normal cerebellar development but susceptibility to seizures in mice lacking G-protein-coupled, inwardly rectifying $\mathrm{K}^{+}$channel GIRK2. Proc Natl Acad Sci USA 94:923-927.

Smart SL, Lopantsev V, Zhang CL, Robbins CA, Wang H, Chiu SY,
Schwartzkroin PA, Messing A, Tempel BL (1998) Deletion of the Kv1.1 potassium channel causes epilepsy in mice. Neuron 20:809-819.

Spitzer NC, Lamborghini JE (1976) The development of the action potential mechanism of amphibian neurons isolated in cell culture. Proc Natl Acad Sci USA 73:1641-1645.

Wahlestedt C, Golanov E, Yamamoto S, Yee F, Ericson H, Yoo H, Inturrisi CE, Reis DJ (1993) Antisense oligodeoxynucleotides to NMDA-R1 receptor channel protect cortical neurons from excitotoxicity and reduce focal ischemic infarctions. Nature 363:260-263.

Wang Z, Feng J, Shi H, Pond A, Nerbonne JM, Nattel S (1999) Potential molecular basis of different physiological properties of the transient outward $\mathrm{K}^{+}$current in rabbit and human atrial myocytes. Circ Res 84:551-561.

Xu J, Yu W, Jan YN, Jan LY, Li M (1995) Assembly of voltage-gated potassium channels. Conserved hydrophilic motifs determine subfamilyspecific interactions between the $\alpha$-subunits. J Biol Chem 270:24761-24768.

Yu C, Brussaard AB, Yang X, Listerud M, Role LW (1993) Uptake of antisense oligonucleotides and functional block of acetylcholine receptor subunit gene expression in primary embryonic neurons. Dev Genet 14:296-304.

Zhou L, Zhang CL, Messing A, Chiu SY (1998) Temperature-sensitive neuromuscular transmission in Kv1.1 null mice: role of potassium channels under the myelin sheath in young nerves. J Neurosci 18:7200-7215.

Zhou L, Messing A, Chiu SY (1999) Determinants of excitability at transition zones in Kv1.1-deficient myelinated nerves. J Neurosci 19:57685781. 